Linha D'Água (Online), São Paulo, v. 33, n. 2, p. 137-159, maio-ago. 2020

\title{
INVESTIGAÇÕES SOBRE O TRABALHO DO CLASSICISTA DIGITAL: APORTES INICIAIS
}

\section{RESEARCHING ON THE DIGITAL CLASSICIST WORK: INITIAL CONSIDERATIONS}

\author{
Michel Ferreira dos Reis* \\ Universidade Paulista Júlio de Mesquita Filho, Araraquara, SP, Brasil
}

\begin{abstract}
Resumo: 0 presente artigo tem a finalidade de trazer uma contribuição em relação ao trabalho do professor e pesquisador de línguas clássicas, mais especificamente, 0 de língua/literatura grega, que vem se apoiando em métodos e tecnologias digitais para o estudo, pesquisa e ensino da antiguidade. Em tal empreitada, usaremos as fundamentaç̦̃os teórica e metodológica do Interacionismo Sociodiscursivo (BRONCKART, 2006, 2008, 2012) e nos valemos do conceito de gênero professional (CLOT; FAïTA, 2000) advindo da Clinica da Atividade. Dessa forma, para a análise da pesquisa que ainda está em desenvolvimento, teremos como o foco neste artigo os dados coletados de duas entrevistas com um professor/pesquisador do curso de Humanidades Digitais, mas que é um classicista digital. A partir disso, ser̃̃o apontados aspectos relativos à percepcçoo do seu trabalho numa perspectiva interdisciplinar entre Humanidades e Informática.
\end{abstract}

Palavras-chave: classicista digital; ;rabalho; ISD, gênero profissional, classicismo digital.

Abstract: This article aims at contributing to the investigations of the work of the teacher and the researcher of classical languages, specifically the Greek language / literature, which has been relying on digital methods and technologies for the study, research and teaching of antiquity. In this endeavor, we will use the theoretical and methodological framework of Sociodiscursive Interactionism (BRONCKART, 2006, 2008, 2012) and use the concept of professional genre (CLOT; FAïTA, 2000) from the Clinic of Activity. Thus, for the analysis of research that is still under development, we will focus on this article the data collected from two interviews with a teacher / researcher of the Digital Humanities course, but who is a digital classicist. Thus, aspects related to the perception of his work will be pointed out in an interdisciplinary perspective between Humanities and Informatics.

Keywords: Digital Classicist; Work; SDI; Professional Genre; Digital Classicism.

* Doutorando da Universidade Paulista Júlio de Mesquita Filho - UNESP, Araraquara, SP, Brasil; https://orcid.org/0000-0003-201 8-4188; michelfereis@gmail.com

hitp://dx.doi.org/10.11606/issn.2236-4242.v33i2p137-159 
Linha D'Água (Online), São Paulo, v. 33, n. 2, p. 137-159, maio-ago. 2020

\section{Introdução}

Este texto pretende trazer contribuições iniciais para investigação sobre o trabalho dos classicistas digitais. Esses profissionais são professores e pesquisadores que investigam e ensinam sobre a antiguidade clássica, em diversas áreas das Humanidades, "tais como Língua, Literatura, História, Filosofia, Mitologia, Religião, Sociologia, Antropologia, Arqueologia, Linguística, Geografia etc.” (SBEC, 2019)1, e que tradicionalmente são chamados classicistas. $\mathrm{O}$ acréscimo do adjetivo digital que vem sendo empregado junto a classicista, ou Classicismo, evidencia uma tendência dentro das Ciências Humanas que é a inserção de tecnologias digitais por parte de grupos de profissionais em suas atividades diárias de trabalho de ensino, pesquisa e divulgação científica. Em relação aos classicistas, surge uma diferenciação primordial de dois grupos profissionais: de um lado, o classicista tradicional e de outro o classicista digital. A determinação de tais grupos, embora pareça simplista e podendo às vezes ignorar, sem pretensão alguma, a complexidade e diversidade das atividades humanas, nas quais ora um sujeito esteja trabalhando em um sentido mais tradicional, ora trazendo recursos ou métodos que sejam do plano digital, é vital para este artigo. Dessa forma, é válido estabelecer de que ponto de vista falamos. O uso do termo digital é uma necessidade de apontar que algumas atividades desenvolvidas nas últimas décadas dentro campo dos Estudos Clássicos vem convergindo para a adoção das tecnologias digitais que eram quase que exclusivamente e costumeiramente aplicadas em outros campos do conhecimento que não nas Humanidades, entretanto, devemos deixar bem delineado que a simples apropriação de um artefato tecnológico não torna um classicista em classicista digital.

Nesse sentido, ainda podemos pensar em uma diferenciação de dois grupos dentro do Classicismo Digital: de um lado teríamos os classicistas digitais que estariam na vanguarda da criação de ferramentas computacionais, corpora linguísticos e edições digitais de livros ou de dados digitais; de outro, teríamos os classicistas da era digital que não estariam associados ao trabalho de criação de ferramentas propriamente dito, mas se apropriariam das ferramentas criadas pelos

1 Trecho retirado da página oficial da Sociedade Brasileira de Estudos Clássicos. Disponível em <https://www.classica.org.br/conteudo/view?̦ID_CONTEUDO=270> Acesso em 01 out. 2019

REIS, M. F. Investigações sobre o trabalho do classicista digital: aportes iniciais 
primeiros em suas atividades de trabalho. Desse modo, os classicistas digitais estariam conectados/relacionados mais à informática e à programação; enquanto os da era digital usam os artefatos criados, vindo também a criar dados digitais visto que a maioria dos produtos e serviços dos quais se apropriam tem a finalidade de produzir mais dados para o ambiente digital, em um processo de retroalimentação entre os primeiros e os últimos: a) criamos para serem usados, b) usamos para criarmos, investigarmos, educarmos e c) reutilizamos para recriarmos.

Assim exposto, no presente artigo será conduzido um estudo sobre os classicistas digitais sem fazer uma distinção entre quem produz ou quem usa as tecnologias. Desse modo, o artigo se pauta na análise de duas entrevistas orais aplicadas a um professor/pesquisador ${ }^{2}$ em uma universidade na Alemanha, tendo a fundamentação teórica baseada na análise de textos do Interacionismo Sociodiscursivo (BRONCKART, 2006, 2008, 2012) em diálogo com as Ciências do Trabalho, mais especificamente a Clínica da Atividade. (CLOT; FAÏTA, 2000)

\section{Aportes linguísticos do Interacionismo Sociodiscursivo}

A perspectiva teórica do Interacionismo Sociodiscursivo (doravante ISD) se forma baseada nas perspectivas teóricas interacionistas sociais de três áreas: a) da sociologia de Habermas, quanto à concepção do agir e aos mundos representados como o mundo objetivo, mundo social e mundo subjetivo; b) da psicologia de Vygotsky e seu conceito de instrumento psicológico da teoria do desenvolvimento e c) e dos estudos linguísticos de Sausurre quanto aos signos, e Bakhtin e Volochinov e seus estudos discursivos. Aqui as três vertentes têm em comum o papel central da linguagem e interação nos processos, respectivamente, de socialização, desenvolvimento psicológico e constituição discursiva e dos textos. Sobre a linguagem no ISD, Bronckart (2006) afirma que

No desenvolvimento da tese partilhada por Saussure e Vygotsky, segundo a qual os signos linguageiros fundam a constituição do pensamento consciente humano,

2 Será usado o gênero gramatical masculino como forma neutra para se referir ao participante da pesquisa.

REIS, M. F. Investigações sobre o trabalho do classicista digital: aportes iniciais

Todo conteúdo da Linha D'Água está sob Licença Creative Commons Attribution-NonCommercial 4.0 International License 
o ISD visa demonstrar que as práticas linguageiras situadas (ou os textos-discursos) são os instrumentos principais do desenvolvimento humano, tanto em relação aos conhecimentos e os saberes quanto em relação às capacidades do agir e da identidade das pessoas. (BRONCKART, 2006, p. 10)

Bronckart $(2006,2008,2012)$, pautado nas vertentes acima, desenvolve a teoria interacionista sociodiscursiva, na qual a linguagem se caracteriza como um instrumento mediador de relações sociocomunicativas nas quais o indivíduo constrói representações do mundo pelo intermédio dos textos orais ou escritos. Para o autor, o agir humano é dado pelas práticas sociais que se definem com o agir linguageiro, processo tal que se formaliza pelos textos, ou melhor, pelos gêneros de textos, visto a diversidade das atividades humanas. Nesse sentido, o agir linguageiro está diretamente relacionado à atividade (ou trabalho) realizada por um indivíduo, portanto é possível compreendê-la focalizando os textos e seus respectivos elementos constituintes e produzidos, entretanto, torna-se necessário definir os elementos do agir humano e sua relação com os textos.

Primeiramente, o ISD tem em seu quadro teórico conceitos como o agir, atividade e ação que são fulcrais para o entendimento das ações humanas. Bronckart (2006) define genericamente o agir como

Qualquer comportamento ativo de um organismo. Se todas as espécies mostram a existência de formas de agir socializado e, principalmente, de um agir comunicativo (visando aos congêneres de cada espécie), a espécie humana é, aparentemente, a única a ter operacionalizado um agir comunicativo verbal, mobilizando signos organizados em textos, que lhe permitem construir um espaço gnoseológico, ou seja, mundos de conhecimentos que podem se tornar autônomos em relação às circunstâncias individuais da vida, que podem se acumular no curso da história dos grupos. Portanto, para essa espécie em particular, é necessário distinguir, por princípio, um agir não verbal, que chamaremos de agir geral, e um agir verbal, que chamaremos de agir de linguagem. (BRONCKART, 2006, p. 137, grifo nosso)

Além dessa definição, conforme Bronckart e Machado (2009), o termo agir pode ser usado para situações em que se encontra uma intervenção humana no plano do mundo real e que estarão em análise; já atividade seria uma interpretação 
de um agir pensado coletivamente, enquanto ação seria em um plano individual, ambas definidas posteriores ao processo de análise. Esses conceitos não podem ser observados diretamente, mas passam por uma interpretação por meio de textos orais ou escritos.

Em segundo lugar, os textos são direcionados pelas atividades humanas devido ao seu caráter dialógico e interacional, mostrando sua intrínseca dependência entre o contexto de produção (mundo físico) e a estrutura formal/linguística com a qual se desenvolve, além disso, vindo a se organizar em gêneros de texto; consequentemente, os textos trazem indícios sobre as atividades humanas, uma vez que se organizam em torno delas. Dessa forma, Bronckart (2012) entende o texto como um folhado textual que consiste em a) infraestrutura geral do texto - com o plano global (conteúdo temático), os tipos de discurso, as sequências; b) mecanismos de textualização - que contribuem para a progressão temática do texto, e c) mecanismos enunciativos - como a identificação de posicionamento (vozes) e avaliações quanto ao conteúdo temático (modalizações). Ademais, Bronckart e Machado $(2009)^{3}$ propõem que os textos passem por procedimentos de análises em níveis/ camadas, do nível mais superficial ao mais profundo: 1) o nível organizacional, que abrange a infraestrutura geral do texto e mecanismos de textualização; 2) o nível enunciativo, que corresponde aos mecanismos enunciativos e 3) nível semântico, visto que aborda os elementos do agir (atividade, ator, agente, instrumentos etc.) e figuras de ação (padrão, canônica, ocorrência, acontecimento etc).

\section{Aportes teóricos quanto ao trabalho}

Segundo Bronckart "o trabalho é uma forma de agir, ou uma prática, que seria própria da espécie humana" (2008, p. 93), assim, para o autor, o trabalho seria uma forma de organização coletiva organizada com a finalidade de produção material. Além do ISD, as contribuições da Psicologia do Trabalho se demonstram relevantes para a pesquisa, mais especificamente da Clínica da Atividade, na qual adotam o conceito de gênero do métier, também chamada de gênero de atividade (CLOT;

3 Os conceitos não serão detalhados nesta seção, mas conforme aparecerem nos exemplos da análise dos dados em 3. Aspectos metodológicos.

REIS, M. F. Investigações sobre o trabalho do classicista digital: aportes iniciais 
Linha D'Água (Online), São Paulo, v. 33, n. 2, p. 137-159, maio-ago. 2020

FAÏTA, 2000), que se preocupa em compreender os elementos da transformação do trabalho.

Clot (2007) institui que o

trabalho é sem dúvida um dos gêneros principais da vida social em seu conjunto, um gênero de situação do qual uma sociedade dificilmente pode abstrair-se sem comprometer sua perenidade; e da qual um sujeito dificilmente pode afastar-se sem perder o sentimento de utilidade social a ele vinculado, sentimento vital de contribuir para essa perenidade, em nível pessoal (CLOT, 2007, p. 69)

Segundo a vertente clássica das Ciências do Trabalho, esse pode se dividir entre o trabalho prescrito e o real, entre a prescrição social e a atividade real, ou entre a tarefa e a atividade. $O$ trabalho prescrito é aquele que segue as normas e modelos pré-estabelecidos pelas instituições reguladoras de trabalho, é o trabalho antes de sua realização, podendo pensá-lo também como o trabalho idealizado. $O$ trabalho realizado é aquele concretamente efetivado, realizado conforme as normas e instruções prescritas, mesmo que não tenha saído do que jeito que se almejava. A partir dessa dicotomia prescrito X realizado, Clot $(2001,2007)$ traz a ideia de trabalho real que não se limita mais a tal dualidade, mas a amplia, ao determinar que aquilo que foi pretendido, mas não alcançado, se associa a trabalho, de forma que o trabalho real seria a soma das prescrições, das realizações e das frustações da atividade do trabalho.

Junto a essa noção, Clot (2007) desenvolve o conceito de gênero profissional, em analogia aos gêneros textuais, o qual consiste ser um elemento intermediário nas atividades, ou seja, existe uma história do coletivo compartilhada que se caracteriza como o gênero social do métier, que define a regulação das ações individuais. Isso significa que os trabalhadores compartilham regras e modos de agir que não estão prescritos nos documentos oficiais e institucionais, mas que são esperados como modelos de comportamentos ou atitudes, uma vez que compartilham de uma memória social e coletiva que serve como reportório. É na perspectiva de gênero profissional de Clot (2007) e de Clot e Faïta (2000) que este artigo se baseia para estudar o trabalho do classicista digital, no qual se vale de corpora orais para coleta dos dados, mais especificamente, as duas entrevistas. 
Linha D’Água (Online), São Paulo, v. 33, n. 2, p. 137-159, maio-ago. 2020

\section{Aspectos metodológicos}

$\mathrm{O}$ artigo segue uma orientação qualitativa de pesquisa por meio de estudo de caso e se apropria dos procedimentos metodológicos da Clínica da Atividade para a coleta dos dados, por meio de entrevistas, = e das contribuições do Interacionismo Sociodiscursivo para a análise linguística dos dados coletados, almejando a compreensão de elementos que revelem o trabalho do classicista digital, conforme será descrito adiante.

\section{a) Caracterização do local de coleta de dados e do participante}

A coleta de dados foi realizada em uma universidade alemã que possui a graduação e o mestrado em Humanidades Digitais. O motivo da coleta ter sido no exterior se explica pelo fato de a problemática investigada ainda ser escassa no Brasil, ainda mais se nos direcionarmos para a intersecção Informática/Computação e Estudos Clássicos. Dessa forma, e uma vez que nos pautamos no quadro teórico e metodológico do ISD e da Clínica da Atividade, os dados linguísticos foram obtidos por meio de entrevistas ${ }^{4}$ em língua inglesa, visto que se trata de uma língua estrangeira tanto para o participante/informante quanto para o pesquisador, além de ser a língua requerida para o ingresso no curso na universidade de estudo.

O participante é professor do curso de Humanidades Digitais, alocado no departamento de mesmo nome, localizado na Faculdade de Computação e Matemática da universidade. Oficialmente, o bacharelado de Humanidades Digitais se inicia em 2016, porém atividades ligadas à área já haviam sido realizadas e planejadas anteriormente, antes da oficialização da implantação do curso, tendo o professor informante desse trabalho participado desde seu começo. Atualmente, os cursos de graduação e mestrado contém quatro professores/pesquisadores, sendo três com formação inicial em Estudos Clássicos e um na área da computação, para

\footnotetext{
4 Na pesquisa, foram realizadas entrevistas e a instrução ao sósia, que consiste em uma simulação na qual o pesquisador (sósia) pede instruções para o trabalhador (participante), como se fosse substituí-lo em um dia de trabalho. Como a pesquisa está em andamento, neste artigo são focalizadas somente as entrevistas.
}

REIS, M. F. Investigações sobre o trabalho do classicista digital: aportes iniciais 
Linha D'Água (Online), São Paulo, v. 33, n. 2, p. 137-159, maio-ago. 2020

ministrar aulas e orientar pesquisas que se concentram em seis projetos guardachuva: 1) Treebank (árvore sintática) de dependência de Latim e Grego antigo; 2) Projeto filologia global; 3) Textos fragmentários, 4) Catálogo de manuscrito; 5) Latim e Grego abertos e 6) Persa aberto. Nota-se que, embora o curso seja voltado para questões gerais e diversas nas Humanidades, há uma predominância de trabalhos e projetos relacionados aos Estudos Clássicos e de Língua e Literatura Gregas, fator importante para a escolha da sede de estudo e coleta de dados.

Ainda sobre o participante: é formado em Estudos Clássicos (Grego/Latim) na Itália, onde realizou também seus estudos de mestrado e doutorado. Teve seus primeiros contatos com Clássicas e recursos digitais por meio de suas aulas de graduação, nas quais ele e seus colegas obtiveram acesso ao acervo do Thesaurus Linguae Graecae, que é uma biblioteca digital de literatura grega disponível on-line na internet, mas que antigamente era disponível em CD-ROMs e deveria ser instalada em um computador pessoal para acesso. Seu pós-doutoramento, realizado na Universidade Tufts nos EUA, onde ministrou aulas de literatura utilizando recursos digitais, despertou um interesse maior em trabalhar com métodos digitais na pesquisa e ensino de línguas históricas e, dessa forma, vem trabalhando há dez anos com $\mathrm{Hu}$ manidades Digitais, mais especificamente, na área de Clássicas e Filologia Digitais.

\section{b) Procedimentos de coleta de dados}

Foram realizadas duas entrevistas semiestruturadas e uma instrução ao sósia. Para o presente artigo, focaremos somente as entrevistas. A primeira (Anexo A) foi aplicada na primeira parte do semestre de inverno de 2018-2019 no mês de novembro, conforme o calendário acadêmico alemão que compreende outubro -março. O objetivo era trazer questões mais gerais sobre a carreira profissional, suas aulas, as pesquisas, a instituição e o perfil dos alunos. A gravação foi feita por dois aparelhos: a) uma câmera filmadora HandyCam Sony HDR-CX405 HD para vídeo; e b) o gravador de áudio de um celular Windows Phone - Lumia 640 $\mathrm{X}$, como alternativa, caso a filmadora não funcionasse.

A segunda entrevista foi realizada após o recesso acadêmico do final do ano e foram feitas questões mais pontuais baseadas nas respostas da primeira entrevista 
Linha D'Água (Online), São Paulo, v. 33, n. 2, p. 137-159, maio-ago. 2020

(Anexo B). Dessa vez, a gravação foi feita pelo gravador de áudio do Windows Phone Lumia $640 \mathrm{X}$, pois a filmadora foi programada para gravar, mas não funcionou.

\section{c) Procedimentos para transcrição e análise}

Posteriormente às gravações, os arquivos foram convertidos para a extensão de áudio WAV, a fim de serem usados no software EXMARaLDA - Partitur para transcrição das entrevistas. O software Partitur é uma das ferramentas do sistema ExMARaLDA ${ }^{5}$ que consiste na criação, gerenciamento e análise de corpora orais digitais. No caso, o Partitur é a ferramenta disponível para a criação de transcrição. Conforme podemos observar na figura 1, o programa permite a inserção de alguma mídia em áudio ou vídeo, que tem a exibição das ondas sonoras e da cronometragem no espaço em amarelo indicado pelo número 1, enquanto a transcrição é realizada na caixa abaixo em cinza indicado pelo número 2 .

Fig. 1: Interface do Partitur

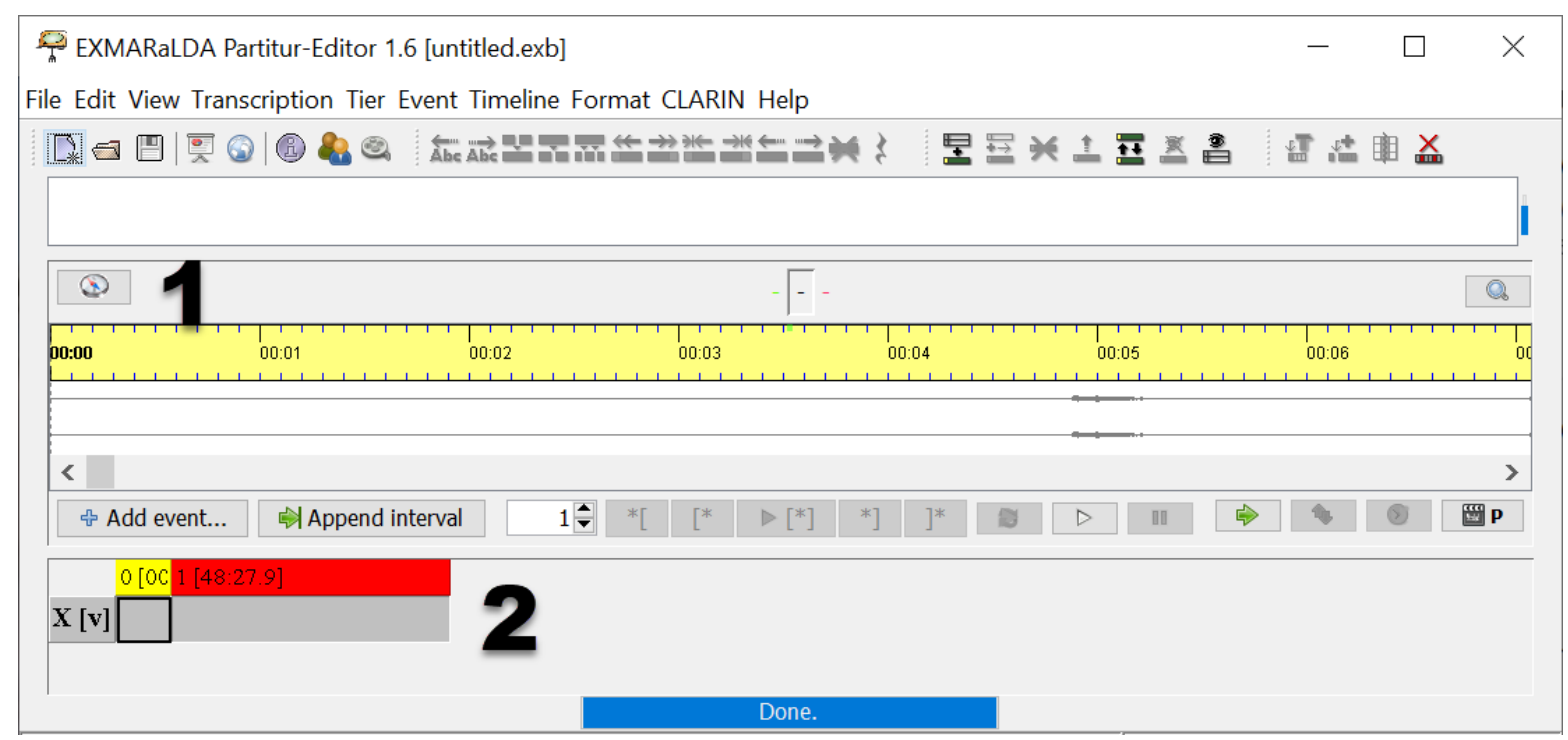

5 Informações sobre o ExMARaLDA, acessar: <https://exmaralda.org/en/>. Acesso em 20 nov 2019.

REIS, M. F. Investigaçōes sobre o trabalho do classicista digital: aportes iniciais

Todo conteúdo da Linha D'Água está sob Licença Creative Commons Attribution-NonCommercial 4.0 International License 
Linha D’Água (Online), São Paulo, v. 33, n. 2, p. 137-159, maio-ago. 2020

A configuração mais significativa para o uso dessa ferramenta se deve principalmente à sua gama de opções e maleabilidade que oferece. Embora tenha sido desenvolvida para o manejo de corpora oral digital e apresente uma diversidade de funcionalidade, a ferramenta é muito útil no sentido em que permite ao pesquisador determinar suas próprias orientações de transcrições e categorias de análise, além de se poder manipular e importar textos originalmente escritos. A versatilidade e usabilidade do programa neste projeto se mostram primordialmente pela capacidade dos corpora serem transcritos, analisados e anotados em camadas. Como veremos adiante, as camadas aparecem em formato de linhas, nas quais é inserido o texto na primeira, e nas demais, as anotações.

\section{d) Categorias iniciais para análise}

As categorias para investigação da atividade profissional do classicista digital são baseadas principalmente no Interacionismo Sociodiscursivo (BRONCKART, 2006, 2008, 2012) em diálogo com as contribuições das Ciências do Trabalho, Ergonomia do Trabalho e Clínica da Atividade (CLOT; FAÏTA, 2000), pesquisas que se apoiam na investigação e intersecção do trabalho do professor/pesquisador por meio da análise textual (BRONKCART; MACHADO, 2009) e que investigam a interpretação de atividade profissional (BULEA, 2010). Desse modo, faz-se possível avaliar os textos seguindo as seguintes categorias: 
Quadro 1: Níveis procedimentais de análise textual, baseado em Bronckart (2006, 2008, 2012), Bronckart e Machado (2009) e Bulea (2010)

\begin{tabular}{|c|c|}
\hline 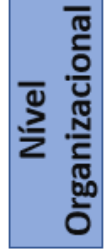 & $\begin{array}{c}\text { Plano global } \\
\text { Tipos de discurso } \\
\text { Tipos de sequência de textos } \\
\text { Mecanismos textuais }\end{array}$ \\
\hline 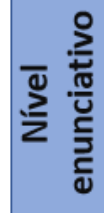 & $\begin{array}{c}\text { Marcas de pessoa } \\
\text { Dêiticos de tempo e espaço } \\
\text { Vozes } \\
\text { Modalizações }\end{array}$ \\
\hline 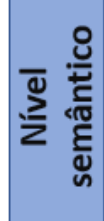 & $\begin{array}{c}\text { Elementos do agir } \\
\text { (Atividade, ator, intenções, motivos) } \\
\text { Elementos da ação } \\
\text { (ocorrência, acontecimento passado, } \\
\text { experiência, canônica, definição) }\end{array}$ \\
\hline
\end{tabular}

No nível organizacional, temos o plano global, que trata do conteúdo temático do texto. Os tipos de discursos são os segmentos presentes nos textos e os compõem em diferentes gêneros. Os tipos de sequências são os modos de planificação/ de organização sequencial do texto, podendo ser narrativa, argumentativa, injuntiva, descritiva, explicativa e dialogal. Já os mecanismos textuais ou de textualização contribuem para a coerência textual dando progressão temática e são formados pelos conectivos e pela coesão nominal e verbal.

O nível enunciativo se refere à coerência pragmática do texto e é formado pelas marcas de pessoas, pelas vozes que indicam um posicionamento em relação ao que é enunciado e, por fim, pelas modalizações que são avaliações sobre tópicos do conteúdo temático.

O nível semântico é considerado o nível micro no qual as atitudes são reinterpretadas baseadas em uma semântica do agir. Assim, apresenta os elementos do agir que servem para a interpretação de condutas ou comportamento como 
Linha D'Água (Online), São Paulo, v. 33, n. 2, p. 137-159, maio-ago. 2020

atividade, ação, ator, agente, instrumentos; além das figuras de ação ${ }^{6}$, que se configuram como figuras interpretativas do agir.

\section{e) Dados das entrevistas}

As duas entrevistas semiestruturas foram aplicadas em dois momentos distintos com o professor/pesquisador participante: a primeira, em novembro de 2018, e a segunda, em fevereiro de 2019, totalizando 1 hora, 12 minutos e 38 segundos. $\mathrm{Na}$ primeira (ANEXO A), as questões foram mais generalistas, com a finalidade de levantar tópicos gerais quanto à pesquisa, ao ensino e à instituição educacional; na segunda (ANEXO B), direcionada pela primeira entrevista, almejou-se retomar aspectos que poderiam ser mais explorados e explicitados verbalmente pelo informante da pesquisa.

\section{Primeiras considerações sobre os classicistas digitais: dados parciais}

Visto que a pesquisa está em andamento, serão abordados nesta seção alguns exemplos de dados que passaram por uma primeira análise, a fim de trazer indícios iniciais sobre a atividade do classicista digital em seu papel de professor e pesquisador sobre o mundo antigo grego.

\section{a) Pessoas e vozes}

A figura 2 é o primeiro exemplo do uso da ferramenta Partitur para realizar as transcrições e para as análises. Como os procedimentos de análise do ISD são feitos por camadas, o programa permite, de certa forma, uma transposição dessa metodologia. Se observarmos a figura 2, nota-se na primeira linha ou camada a entrevista transcrita, logo abaixo os falantes são informados (professor-pesquisador ou entrevistador). Em seguida, as categorias de análise foram estipuladas de

\footnotetext{
6 Sobre as figuras de ação: BULEA, E. Linguagem e efeitos desenvolvimentais da interpretação da atividade. Tradução: Eulália Vera Lúcia Fraga Leurquin, Lana Lúcia Espínola Rodrigues Figueirêdo. Campinas, SP: Mercado de Letras, 2010.
}

REIS, M. F. Investigaç̦ões sobre o trabalho do classicista digital: aportes iniciais 
acordo com o que foi explorado na seção de Aspectos metodológicos, partindo do nível organizacional até o nível semântico de um texto. Isso é representado por cada linha (ou camada) de anotação, dentre elas, plano global, tipos de discurso, sequências, mecanismos textuais, marcas de pessoas, dêiticos, vozes, modalizações, elementos do agir e elementos do agir.

Fig. 2: Exemplo de pessoas e vozes

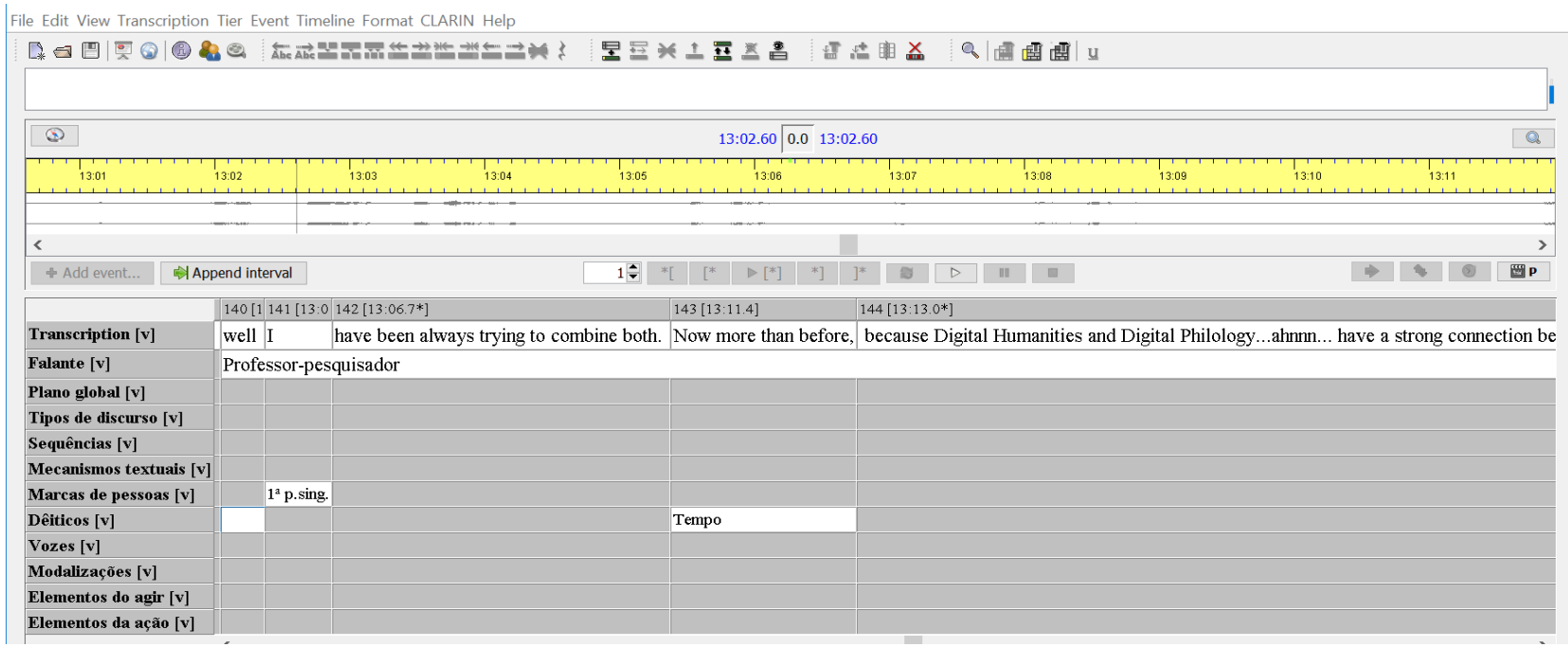

Neste excerto da entrevista, o professor/pesquisador participante é questionado sobre a relação da pesquisa e ensino em suas aulas, e nos informa o seguinte:

[...]I have been always trying to combine both. Now more than before, because $D i-$ gital Humanities and Digital Philology... ahnnn... have a strong connection between teaching and researching, because we need to produce a lot of digital data and so we have the idea is to help students to work on the data and to produce them. [...] (13min $01 \mathrm{~s}-13 \mathrm{~min} 32 \mathrm{~s}$ da $1^{\mathrm{a}}$ entrevista, grifo nosso)

Tradução: Eu estive tentando combinar ambos. Agora mais do que antes, porque $H u-$ manidades Digitais e Filologia Digital... ahnnn... tem uma forte conexão entre ensino e pesquisa, porque nós precisamos produzir muitos dados digitais e, portanto, nós temos a ideia que é ajudar alunos a trabalhar com dados e produzi-los. [...] (13min 01s - 13 $\min 32 \mathrm{~s}$ da $1^{\mathrm{a}}$ entrevista, grifo nosso)

REIS, M. F. Investigaçōes sobre o trabalho do classicista digital: aportes iniciais Todo conteúdo da Linha D'Água está sob Licença Creative Commons Atribibution-NonCommercial 4.0 International License 
Percebe-se que o participante usa duas marcas de pessoas ( $I$ - eu e we - nós) para abordar o tema em questão. Inicia a sua fala em primeira pessoa do singular, $I(\mathrm{eu})$, demonstrando a particularidade e experiência própria quanto ao entendimento e relação entre a pesquisa e ensino nas suas aulas, e move, saindo de uma voz particularizada e pessoal, para um segundo momento, para a primeira pessoa do plural, we (nós), referindo-se a um coletivo das Humanidades Digitais ou mesmo do coletivo de trabalhadores em sua instituição. A ambiguidade de we - nós pode ser verificada pelo fato de que o informante ao dizer "porque nós precisamos produzir muitos dados digitais", esteja mais próximo na cadência sintática do texto a "Humanidades digitais e filologia digital”, enquanto que a afirmação "portanto, nós temos a ideia que é ajudar alunos a trabalhar com dados e produzi-los" poderia ser um retorno ao início de sua fala e situação particularizada quando usa $I-e$ u. Entretanto, o mesmo trecho poderia indicar simplesmente uma generalização e uma não implicação do sujeito na ação em si nas duas vezes do aparecimento de nós.

\section{b) Modalização}

As modalizações são avaliações do falante em relação ao plano temático do texto (BRONCKART, 2012) e são de quatro tipos: epistêmica ou lógica, que traz grau de veracidade ou certeza; deôntica, que expressa valor, dever ou obrigação; apreciativa, que revela uma valoração subjetiva do falante; e a pragmática, que indica questões de responsabilidade quanto aos próprios atos.

Fig. 3: Exemplo de modalização

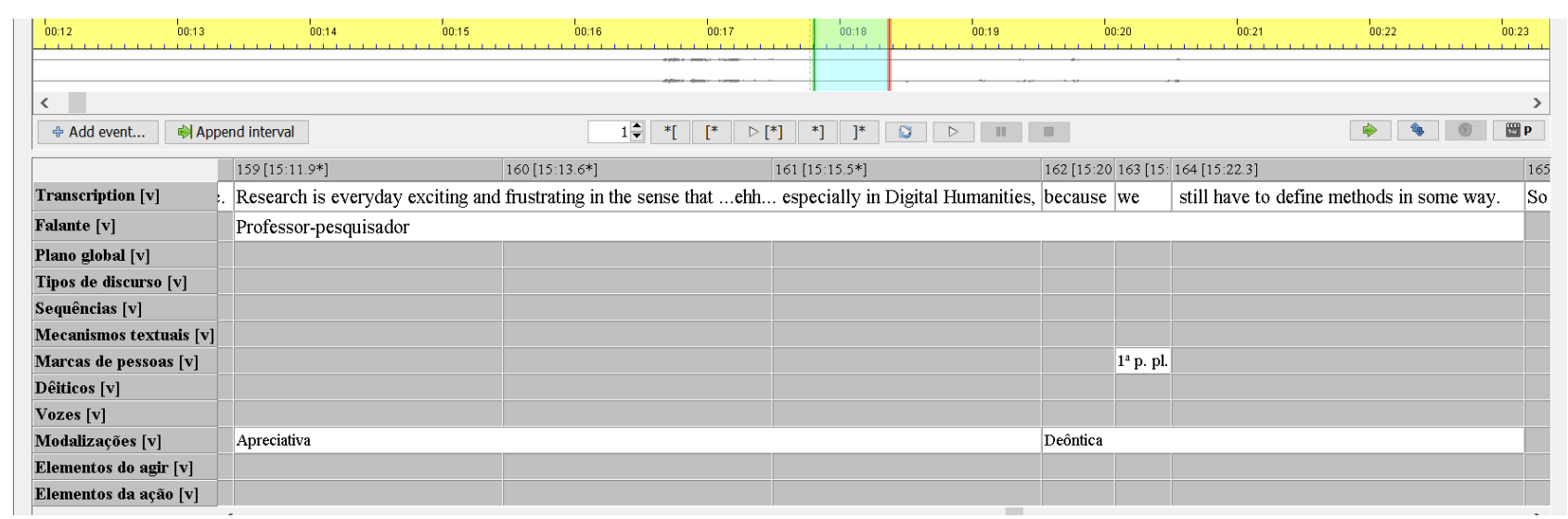

REIS, M. F. Investigações sobre o trabalho do classicista digital: aportes iniciais

Todo conteúdo da Linha D'Água está sob Licença Creative Commons Attribution-NonCommercial 4.0 International License 
Linha D'Água (Online), São Paulo, v. 33, n. 2, p. 137-159, maio-ago. 2020

Conforme observamos na figura 3 e no excerto abaixo, podemos localizar duas modalizações na fala do professor/pesquisador:

In research well... oh, yes! of course. Research is everyday exciting and frustating in the sense that ...ehh... specially in Digital Humanities, because we still have to define methods in some way. ( $15 \min 08 \mathrm{~s}-15 \mathrm{~min} 25 \mathrm{~s}$ da $1^{\mathrm{a}}$ entrevista)

Tradução: Em pesquisa, bem ... oh, sim! Claro. Pesquisa é todo dia emocionante e frustrante no sentido que... eh... especialmente em Humanidades Digitais, porque nós ainda temos de definir métodos de alguma forma. (15 min 08s $-15 \mathrm{~min} 25 \mathrm{~s}$ da $1^{a}$ entrevista)

Retomando o papel da pesquisa no seu trabalho como classicista digital, o professor afirma que a "pesquisa é todo dia emocionante e frustrante no sentido que... eh... especialmente em Humanidades Digitais" e continua "porque nós ainda temos de definir métodos de alguma forma." Na primeira parte da sentença, o enunciador expressa uma avaliação apreciativa (modalização apreciativa), um julgamento subjetivo quanto à pesquisa em sua área, uma vez que, em sua opinião, ela é ao mesmo tempo emocionante (exciting) e frustrante (frustating). Posteriormente, vale-se de uma modalização deôntica, em que determina a causa dessa dualidade que é a obrigação, inerente ao próprio campo de conhecimento, em se definir métodos de estudo, visto que há ainda muitas questões abertas a serem respondidas.

\section{c) Ambientes on-line e colaborativos}

No próximo exemplo (Figura 4), o professor/pesquisador cita os ambientes com e nos quais os humanistas e classicistas digitais têm trabalho: os ambientes on-line e colaborativos. 


\section{Linha D’Água (Online), São Paulo, v. 33, n. 2, p. 137-159, maio-ago. 2020}

Fig. 4: $\mathrm{O}$ ambiente colaborativo

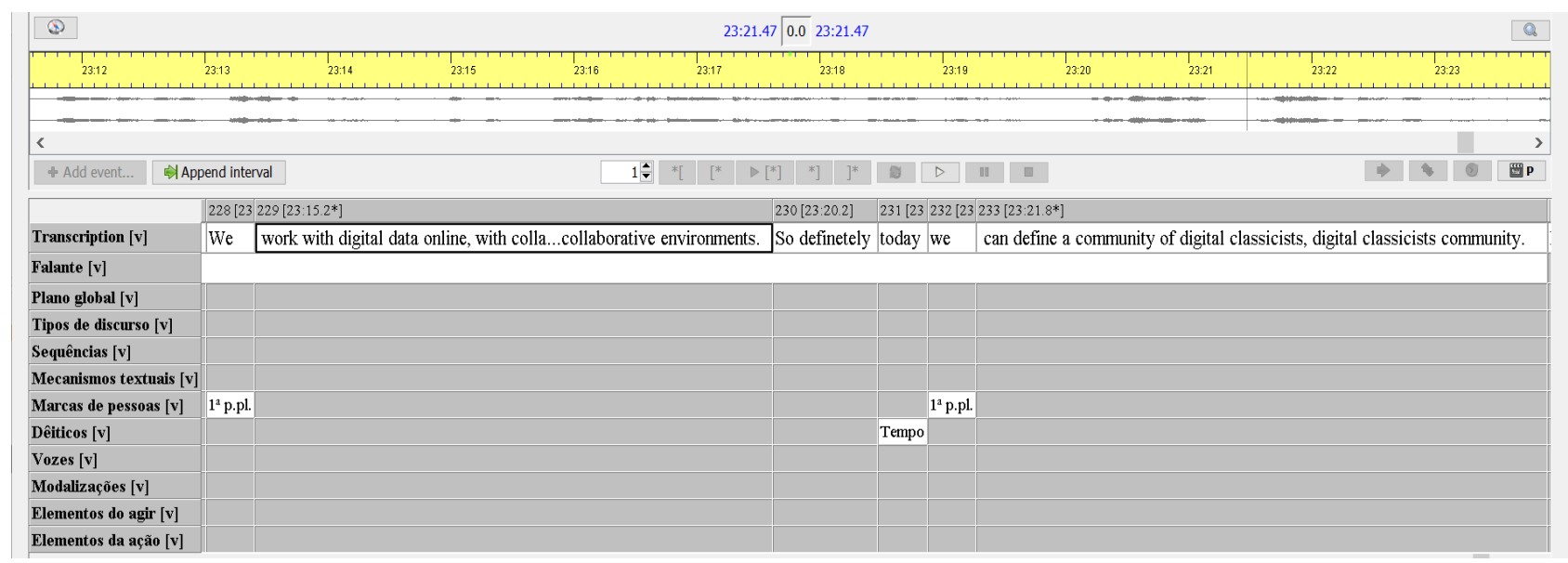

Dessa forma, ao retratar as atividades que são desempenhadas pelos classicistas digitais, o professor/pesquisador comenta:

And then we have different activities like, for example, workshops. Not traditional conferences with scholars read the text, but round tables and workshops where we go and discuss together problems. Then we have online courses, online conferences. We work with digital data online, with colla... collaborative environments. So definitely today we can define a community of digital classicists, digital classicists' community. It's true. It exists. It, it's part of other communities, bigger communities. Yeah. And they share. Community... they share problems and issues. The goal is to talk to other communities, not to be isolated. (22min $54 \mathrm{~s}-23 \mathrm{~min} 45 \mathrm{~s}$ da $1^{\mathrm{a}}$ entrevista, grifo nosso)

Tradução: E então nós temos atividades diferentes como, por exemplo, workshops. Não conferências tradicionais com acadêmicos lendo um texto, mas mesas redondas e workshops onde nós vamos e discutimos juntos problemas. Depois, temos cursos on-line, conferências. Nós trabalhamos com dados digitais on-line, com cola... ambientes colaborativos. Então definitivamente hoje nós podemos definir uma comunidade de classicistas digitais, comunidade de classicistas digitais. É verdade. Existe. É, éparte de outras comunidades, comunidades maiores. Sim. E eles compartilham. Comunidade... eles compartilham problemas e questões. O objetivo éfalar com outras comunidades, não estar (ser) isolado. (22min $54 \mathrm{~s}-23 \mathrm{~min} 45 \mathrm{~s}$ da $1^{\mathrm{a}}$ entrevista, grifo nosso)

Sobre o trecho acima, há duas considerações a serem feitas: sobre os ambientes on-line e colaborativos e sobre os workshops. O participante declara que há REIS, M. F. Investigações sobre o trabalho do classicista digital: aportes iniciais Todo conteúdo da Linha D’Água está sob Licença Creative Commons Attribution-NonCommercial 4.0 International License 
uma diferença entre as atividades exercidas pelos classicistas digitais e as atividades exercidas pelos classicistas ditos tradicionais. O que os distingue seria principalmente os workshops, pois segundo o participante, eles se diferenciam das conferências tradicionais, visto que em tal situação há um objetivo claro que é apresentar os problemas com os quais o pesquisador se depara e, então, compartilhá-los com a intenção de resolvê-los. Outro ponto levantado é o ambiente nos e com os quais trabalham. $\mathrm{O}$ trabalho dos classicistas digitais não é reduzido mais a uma espaço geográfico e físico, porque a pesquisa, dados, resultados e obras dentro das Humanidades Digitais e Clássicas Digitais não se limitam mais a um único lugar, mas sim são ofertados, realizados e compartilhados em ambientes on-line na internet, em diversas plataformas de edição, anotação e leitura de obras, como a Biblioteca Digital Perseu ${ }^{7}$ e o Alpheios ${ }^{8}$.

\section{d) Suporte material}

O último tópico a ser considerado é um dos elementos que poderia vir a diferenciar as Humanidades Digitais. Segundo a fala do participante:

This is the main difference. Of course, today there is a big debate, because we should distinguish between paper Humanities and digital Humanities. So and the discussion needs, do still need the adjective digital for digital humanities? Because there are so many projects using these technologies that maybe we can avoid in some point in the future when we are not using more the adjective digital, but I think we are still far. And the discussion is also that: do you want to separate and distinguish between Humanities, traditional Humanities and digital Humanities? (04min 46s - 05min $28 \mathrm{~s}$ da $2^{\mathrm{a}}$ entrevista)

Tradução: Essa é a principal diferença. Claro, hoje há um grande debate, porque nós deveriamos distinguir Humanidades em papel e Humanidades Digitais. Então e a discussão precisa, ainda precisa do adjetivo digital para Humanidades digitais? Porque

7 Biblioteca Digital Perseu disponibiliza um acervo de obras clássicas em ambiente web. Disponível em: <http://www. perseus.tufts.edu/hopper/> Acesso em 10 nov 2019.

8 Projeto Alpheios é uma plataforma on-line e colaborativa de edição de dados digitais de línguas clássicas. Disponível em: < https://alpheios.net/> Acesso em 10 nov 2019.

REIS, M. F. Investigações sobre o trabalho do classicista digital: aportes iniciais 
Linha D’Água (Online), São Paulo, v. 33, n. 2, p. 137-159, maio-ago. 2020

bá muitos projetos usando essas tecnologias que talvez nós podemos evitar em algum ponto no futuro quando não estivermos usando mais o adjetivo digital, mas eu acho que estamos longe ainda. E a discussão é também essa: você quer separar e distinguir entre Humanidades, Humanidades Tradicionais e Humanidades Digitais? (04min 46s $05 \mathrm{~min} 28 \mathrm{~s}$ da $2^{\mathrm{a}}$ entrevista)

E ainda acrescenta:

Well, traditional Humanities, now, today, but traditional Humanities we refer to mainly, to traditional ways of studying historical documents and publishing the results in printed books. (05min 49s-06min 08s da $2^{a}$ entrevista)

Tradução: Bem, Humanidades tradicionais, agora, hoje, mas Humanidades tradicionais nos referimos a principalmente, a modos tradicionais de estudar documentos bistóricos e publicar os resultados em livros impressos. (05min 49s-06min $08 s$ da $2^{a}$ entrevista)

Para o professor/pesquisador, as Humanidades poderiam ser contrapostas basicamente entre as digitais e aquelas que se pautam no papel. A questão é qual o suporte utilizado pelos profissionais para a publicação e divulgação das áreas e dos conhecimentos produzidos. Levanta-se aqui um ponto importante para discussão, já que se vê corriqueiramente o pensamento de que a produção de materiais ou livros em formato pdf (portable document fle) seria uma versão digital de uma obra. Entretanto, cai-se em uma concepção equivocada do que seria uma publicação ou uma edição digital de um livro, pois, resumidamente, essa precisa ter dados digitais armazenados em bancos de dados ou servidores conectados entre si, com ligações por meio de hiperlinks e enriquecidos pelas anotações linguísticas dentre outros elementos.

\section{Considerações finais}

Fundamentado nos pressupostos teóricos e metodológicos do ISD quanto à análise de texto em associação com a concepção de gênero profissional da Clínica da Atividade (CLOT; FAÏTA, 2000), este artigo trouxe reflexões iniciais sobre o

REIS, M. F. Investigações sobre o trabalho do classicista digital: aportes iniciais

Todo conteúdo da Linha D'Água está sob Licença Creative Commons Attribution-NonCommercial 4.0 International License 
trabalho do classicista digital por meio de duas entrevistas orais. Dessa forma, os resultados evidenciaram aspectos ligados: a) às marcas de pessoas: nas quais há uma oposição entre o trabalho do eu versus nós, o eu classicista versus nós coletivo; b) às modalizações: o participante expressou uma emoção e uma frustação no trabalho de pesquisa dentro do campos das Humanidades Digitais por meio de uma modalização apreciativa, além de revelar uma obrigação na área em ter de definir ainda os métodos de pesquisa, usando assim uma modalização deôntica; c) aos ambientes on-line e colaborativos com e nos quais os classicistas digitais trabalham e d) ao questionamento sobre uma mudança de Humanidades baseadas em edições impressas, ou seja, baseadas em papel versus as Humanidades Digitais. Além disso, ficam ainda alguns questionamentos que precisam ser compreendidos mais detalhadamente como: a) as atividades desempenhas pelos classicistas digitais são as mesmas dos tradicionais?, b) quais os recursos e procedimentos para a pesquisa e ensino? e c) o que é marca de estilo ou de gênero profissional nesse contexto? Logo, com as análises já realizadas e com as futuras, espera-se que sejam levantados mais elementos para que possamos caracterizar o agir do classicista digital, determinando consequentemente aspectos de seu gênero profissional. Assim, junto da determinação de tais características, será possível e necessário ponderar e repensar a formação inicial e continuada dos futuros classicistas.

\section{Referências}

BRONCKART, J. P. Atividade de linguagem, discurso e desenvolvimento humano. Campinas: Mercado de Letras, 2006.

O agir nos discursos: das concepçôes teóricas às concep̧̧óes dos trabalhadores. Campinas: Mercado de Letras, 2008.

. Atividades de linguagem, textos e discursos: por um interacionismo sociodiscursivo. Tradução de Anna Rachel Machado e Péricles Cunha. São Paulo: Educ, 2012.

BRONCKART, J. P.; MACHADO, A. (Re-)Configurações do trabalho do professor construídas nos e pelos textos: a perspectiva metodológica do grupo ALTER-LAEL. In: 
Linha D'Água (Online), São Paulo, v. 33, n. 2, p. 137-159, maio-ago. 2020

ABREU-TARDELLI, L. S.; CRISTOVÃO, V. L. L. (Orgs.). Linguagem e educação: o trabalho do professor em uma nova perspectiva. Campinas, SP: Mercado de Letras, 2009. p. 31-77.

BULEA, E. Linguagem e efeitos desenvolvimentais da interpretação da atividade. Tradução: Eulália Vera Lúcia Fraga Leurquin, Lana Lúcia Espínola Rodrigues Figueirêdo. Campinas: Mercado de Letras, 2010.

CLOT, Y. Clinique de l'activité et pouvoir d'agir. Editorial, Paris, n. 146, p. 7-16, 2001.

- A função psicológica do trabalho. Tradução de Adail Sobral. São Paulo: Vozes, 2007.

CLOT, Y.; FAÏTA, D. Genres et styles en analyse du travail: concepts et méthodes. Travailler, n. 4, p. 7-42, 2000.

SOCIEDADE BRASILEIRA DE ESTUDOS CLÁSSICOS. A SBEC. 2019. Disponível em: https://www.classica.org.br/conteudo/view?ID_CONTEUDO=270 Acesso em 10 dez. 2019.

Recebido: 15/12/2019.

Aprovado: 19/03/2020.

REIS, M. F. Investigaç̃oes sobre o trabalho do classicista digital: aportes iniciais 
Linha D'Água (Online), São Paulo, v. 33, n. 2, p. 137-159, maio-ago. 2020

\section{Anexo A - Primeira entrevista}

1. Please introduce yourself and describe your position at the university.

2. What is your initial background? If possible, describe your undergraduate degree, master and doctoral studies.

3. What was your professional goal when you started your studies? Which profession did you intend to have? What is the connection between it and your current position? 4. What are the courses you teach? Please, describe the subjects, the goals, and requirements. If there are requirements, who determines them?

5. What is the profile of the students? Which fields do they belong to? Can the students from other courses register in your courses?

6. Are there any expectations and disappointments in relation to the work inside and outside the classroom? And in relation to the assignments and supervisions of students?

7. How would you describe your work routine?

8. How is the relationship between research and teaching for you?

9. Are there any unexpected and expected results from teaching or research? How is this managed?

10. How would you describe the institutional support? Examples: Classroom, Computer lab, libraries, tutoring of students, scholarships etc.

11. Are there any interferences in your researches and your teaching?

12. What are the conditions that favor or disfavor the teaching and research work? 13. It's common to observe in scientific sites, books, papers, and lectures the use of the expression "digital community" to refer to a group of researchers working on the Humanities applying digital methods, among them the digital classicists. Could you explain the use of the term "community"? Is it possible to observe some behaviors, activities, subjects, concerns within that community? And in relation to your practices of teaching and researching?

14. How do you see yourself professionally? How would you describe yourself? As a humanist, classicist, linguist, programmer, computer scientist, digital humanist, digital classicist etc. Why?

15. Comment on other topics and issues not discussed above that you find important.

REIS, M. F. Investigações sobre o trabalho do classicista digital: aportes iniciais 
Linha D'Água (Online), São Paulo, v. 33, n. 2, p. 137-159, maio-ago. 2020

\section{Anexo B - Segunda entrevista}

1. In our last interview, you said you are an assistant professor of Digital Humanities. What does that mean? How would you describe Digital Humanities considering that Humanities is a big field...

2. In which sense do Digital Humanities differ from Humanities? Could you explain or describe this fact or the use of "Digital"? Maybe give me an example?

3. What means to be located at the Department of Computer Science and not at the Classics? How does that influence your work?

4. How many professors does the course count with? How is the structure of Digital Humanities courses here? What are the subject matters? Is there turnover of teachers or are the same teachers for each course? Who determines what must be taught?

5. What projects of research do you have here connected to Digital Humanities? And projects involving classical languages?

6. Well, so you teach in bachelor and master courses. How do the courses work? What is the goal of them? Are they the same for both audience or different? How are the students evaluated?

7. What is the role of research in the course of Digital Humanities? What kind of activities are students involved in?

8. In other interview, you said that the goal of the course is to teach methods and I quote "methods that go beyond my specific fields", in another excerpt you say: "in traditional philology... we have defined methods." What methods would those be? 9. How do the students work with own data?

10. Although there are not students from Classics, there is some work with them or with professors of the university from the Department of Classical languages or kind of that?

11. What materials do you prepare and use for teaching and researching? Are they different from traditional classicists? Before working in Digital Humanities, did you have previous experiences of teaching at a university?

12. Do you have any study groups here at the university?

REIS, M. F. Investigações sobre o trabalho do classicista digital: aportes iniciais 
Linha D'Água (Online), São Paulo, v. 33, n. 2, p. 137-159, maio-ago. 2020

13. What kind of contact did you have with Perseus and Thesaurus Linguae Graecae during your studies?

14. In 2009 you had an opportunity of being a visiting scholar at Perseus Project. How was your experience there? What project were you engaged in?

15. How would you relate your journey through Classics and Digital Humanities in the last 10 years?

16. What do you expect from Digital Humanities and Classical Languages for next years or decades. 